tional surgical approaches to this problem are discussed. A technique for laparoscopic repair of a Morgagni hernia is described. The literature on the laparoscopic repair of a Morgagni hernia is reviewed and different operative techniques are discussed.

Key words: Morgagni hernia - Laparoscopic surgery Diaphragmatic hernia - Prosthetic mesh

Correspondence to: C. J. Filipi-Email: cjfilipi@creighton. edu

\section{Pancreatic pseudocyst treated by laparoscopic Roux-en-Y cystojejunostomy}

\section{Report of a case and review of the literature}

E. J. Hagopian, ${ }^{1,2}$ J. A. Teixeira, M. Smith,
F. M. Steichen

${ }^{1}$ Department of Surgery, Institute for Minimally Invasive Surgery, St. Agnes Hospital, White Plains, NY, USA

2 Department of Surgery, New York Medical College, Munger Pavilion, Valhalla, NY 10595, USA

Received: 19 September 1999/Accepted: 10 March 2000/Online publication: 22 Auguss 2000

DOI: $10.1007 / \mathrm{s} 004640040010$

\section{Abstract}

Advances in laparoscopic surgical technique and instrumentation have furthered our ability to perform more complex laparoscopic procedures. We report the case of a 45-yearold man in whom a giant pancreatic pseudocyst developed after biliary pancreatitis. He underwent laparoscopic internai drainage by a Roux-en-Y cyst-jejunal anastomosis after unsuccessful percutaneous drainage. The surgical technique and a review of the current literature is presented. We conclude that although laparoscopic intemal drainage technically is feasible in selected cases, additional data are required to define the role of this surgical approach in the treatment of pancreatic pseudocysts.

Key words: Laparoscopy - Pancreatic pseudocyst Roux-en-Y cystojejunostomy

Correspondence to: J. A. Teixeira-Email: Elle949@ aol.com

\section{An unusual complication after percutaneous drainage of a pancreatic pseudocyst into the stomach}

A. Pleskovic, ${ }^{1}$ M. Sever, ${ }^{\prime}$ D. Vidmar, ${ }^{2}$

R. Zorc-Pleskovic, ${ }^{3}$ O. Vraspir-Porenta ${ }^{3}$

'Department of Gastroenterologic Surgery, University Medical Center,

Zaloška 7, 1000 Ljubljana, Slovenia

${ }^{2}$ Institute of Radiology, University Medical Center, Zalołka 7, 1000

Ljubljana, Slovenia

${ }^{3}$ Institute of Histology and Embryology, Medical Faculty, University of

Ljubljana, Koryekova 2, 1000 Ljubljana, Slovenia

Received: 22 April 2000/Accepted: 23 May 2000/Online publication: 22 August 2000

DOI: $10.1007 / \mathrm{s} 004640040007$

Abstract

In the period between September 1995 and June 1999, we performed percutaneous drainage into the stomach in 12 patients. There were no complications or pseudocyst recurrences on insertion or after endoscopic removal of the catheter, which was left in site for 1 year on average. After endoscopic removal of the drainage catheter, one of the patients presented with a cystic formation in the stomach wall, which caused stomach emptying disorder. Therefore, the patient had to be reoperated. The cyst wall was incised and a part of the cystic wall sampled for histological ex. amination. The cyst was then drained into the isolated Roux loop of the jejunum. Histological findings of the cystic wall specimen showed the presence of granulation tissue and smooth muscle layers with ganglia cells of myenteric nerve plexus. Despite this complication, we believe that percutaneous endoscopically and ultrasonographically guided drainage of pancreatic pseudocyst into the stomach by means of a double pigtail catheter is a good method that yields encouraging results in sonographically selected cases. The position of the drainage catheter needs to be checked endoscopically, and the catheter should be removed only after 1 year.

Key words: Pancreatic pseudocyst - Drainage - Stomach - Double pigtail catheter - Complications

Correspondence to: A. Pleskovic-Email: Alojz. Pleskovic@mf.uni-lj.si 